\title{
In the Margins of One Health: Interspecies Solidarity, Care, and Inequality
}

https://doi.org/10.51897/interalia/FXRL1951

\section{Laura Murray}

New York University

ORCID: 0000-0002-0492-6906

\begin{abstract}
This paper tells the story of two women - a veterinarian and a folk healer - to foster political, environmental, and social conditions in which pastoralists based in the central Indian state of Maharashtra could thrive. For them, this practice of fostering necessarily meant tending to human and nonhuman animals together. The women I followed called this interspeciated practice, One Health. To be sure, they borrowed this term from more economically-dominant and politically-normative international development organizations. When wielded by these institutions, One Health has designated a model for preventing emerging zoonotic diseases, and the pandemics they often cause, through the surveillance of marginal livestock rearing communities, often in the Global South. My interlocutors' projects intersected with One Health-and thus were available for funding from it-insofar as the central conceit of One Health was that human and nonhuman animals can share illness. Yet the politics and ethics of the two were very different. I make this case by ethnographically tracking different modalities of seeing that characterize One Health and its vernaculars. Sight, I argue, operates as a perceptual orientation that initiates a "becoming-with" the world for my interlocutors versus a tool to control it (Dave, 2012). How, I therefore ask, might different ways of apprehending the bonds of human and nonhuman beings reveal how we might yet learn to dwell differently on an exhausted planet?
\end{abstract}

Keywords: feminist anthropology, multispecies ethnography, embodiment and the senses

\section{Introduction}

This story is one of seeing anew. It is an account of relations between humans, animals, plants, and places - once obscure to me - becoming sensible as I followed the practice of one veterinarian and one tribal healer with knowledge of traditional medicine, both women, working at a nonprofit organization called Anthra that was located in the central Indian state of Maharashtra, though the scope of their practice was nationwide. These women sought to foster political, environmental, and social conditions in which marginal farmers and pastoralists could thrive. This practice of fostering necessarily meant tending to human and nonhuman animals together. This was in part because the social, geographical, and economic barriers to health that they looked to upend extended across human medical clinics and veterinary offices alike.

The women I followed - Nitya, the veterinarian, and Sangita, the healer - called this "interspeciated" practice One Health (Livingston and Puar, 2011). The concept of One Health initially arose in the early 2000s after a series of zoonotic outbreaks of West Nile Virus, Ebola Hemorrhagic Fever, Mad Cow Disease, SARS, and Avian Influenza. In response, the Wildlife Conservation Society organized a meeting in New York. They invited major stakeholders in global regimes of development and public health. By 2008, the Food and Agriculture Organization, World Organization for Animal Health (OIE), 
the World Health Organization (WHO), the World Bank, and others came together to publish the book Contributing to One World, One Health: A Strategic Framework for Reducing Risks of Infectious Diseases at the Animal-Human-Ecosystems Interface. In 2018, in the wake of a fresh spate of Ebola and Zika outbreaks across West Africa, the World Bank and its partners published an update to the inaugural framework.

My friends at Anthra had been working in holistic registers of health since the 1990s. However, they more recently adopted the specific term of One Health from these international development organizations. When wielded by more economically-dominant and politically-normative institutions, One Health designated a model for preventing emerging zoonotic diseases, and the pandemics they often cause, through the surveillance of livestock-rearing communities seen as posing the greatest risk to global public health. This produced an emphasis on the Global South that, I argue, recapitulated old colonial tropes of the tropics and filth, which justified intrusive practices of data collection, surveillance, and discipline by institutions of the Global North in the name of the development of the Global South. My interlocutors' projects intersected with One Health - and thus were available for funding from it - insofar as the central conceit of One Health was that human and nonhuman animals can share illness. Yet the politics and ethics of the two were very different. My interlocutors' vernacularization of One Health was a radicalization of it.

Drawing on eighteen months of ethnographic field research in sites of animal husbandry and dairy production in India, six of them specifically in western Maharashtra, in this paper I track the different modalities of seeing that characterize One Health and its vernaculars. Sight, I argue, alternately operates as a perceptual orientation that initiates a "becoming-with" the world for the women I worked with, versus a tool to control it (Dave, 2012). That is, the work of Nitya and Sangita was steeped in a sensory openness unto the world and its vicissitudes. Its tactics assumed that the wellbeing of self and other, human and nonhuman, internal and external were always already mutually made and remade. The two women worked from a place of vulnerability, proximity, and shared stakes rather than mastery, securitization, and hierarchies of developed and developing world; as more dominant paradigms of One Health were prone to do. Sight and technologies of visualization, in short, modulated between being a technology of power and a tactic of counter-hegemonic activism, raising the question: How might different ways of apprehending the bonds of human and nonhuman animality yet teach us something new about what it means to be human? Or to put this differently, how might we cultivate new ways of recognizing ongoing exclusions from the category of "the human," perpetuated by dominant regimes of global public health, development, humanitarian aid, and citizenship?

\section{Human-Animal Porosities}

I met Sangita in December of 2015. She was pure charisma and nerve right from the start. It was then that I first participated in one of her medicine-making workshops that she hosted as a pashu sakhi (animal friend) and vaidya (healer) with Anthra, the NGO I was interning with at the time. Sangita, myself, and a small team of her assistants left early in the morning in a van paid for by Anthra. The 
sun rose as we made our way a couple hours northeast of the city of Pune. We were going to meet a group of Maldhari pastoralists, then stationed in the district of Ahmednagar in Western Maharashtra. This particular group was a cattle-keeping community; they reared world-famous Gir cows and bulls from the state of Gujarat.

We approached their encampment on foot from the road. Sangita hollered, "Ai! Dadi! Kaisi ho?" (Hey! Big sister! How are you?) A woman smiled wide, adjusting her light cotton dupatta as she approached. Sangita and her assistants smiled too, hauling a massive cast-iron karahi out of the car for us to make the medicine in. After gathering everyone and finding a suitable spot to build a fire, Sangita got to work. She roasted camphor powder, mixed in sesame oil, and added frankincense while chatting with the group about the properties of different ingredients she was using, herbal remedies they found effective, their daughters' schooling, their crops, and their relationships with settled villagers. She poured the mixture into cold water and began to knead the concoction like dough. There were titters from the young boys watching from afar. The greenish brown goo, indeed, looked a lot like dung. Sangita smiled with them, unfazed. She knew the balm worked and that was all that mattered.

The balm was one of many traditional medicines that the staff of Anthra promoted in their One Health model. It could be used either on cracked hooves or skin, preventing these fissures from causing secondary health problems for bovine and human producers later down the road. Heel and hoof were not so different when the world was being organized into interfaces that could split or not, get infected or not. Under this rubric, the two could be lumped together into a class of cracked bodily parts. The balm that Sangita was making with the Maldhari women was not species-specific because of the practical intimacy of humans and animals in contexts of pastoralism. In the margins, other ways of organizing biological life - including states of normal and abnormal, healthy and sick - opened up. Species distinctions were not steadfast boundaries, but rather, porous interfaces. Indeed, Nitya claimed that folk remedies of many livestock-rearing communities did not make an ontological distinction of human and animal based in biological conceptions of species. As Anthra's website put it,

There is an artificial separation of livestock care and human medical care; communities do not necessarily view these as two separate streams. Thus, a key component of Anthra's approach is to actively ally resources in human and livestock health.

The website claimed that, from the point of view of a small farmer who might share food, residence, and sickness with their animals, there was no hard and fast distinction between human and nonhuman. 


\section{Practical Intimacy in the Margins}

As I learned during my time with Anthra, semi-nomadic Maldhari shepherds first traveled to Maharashtra during a drought in Gujarat in 1972 (Krätli, 2015: 48). For years, these groups relied on accessing common grazing grounds while also making seasonal deals with sugarcane farmers. Historically, when these deals have been made, during the winter months of October to February, Maldharis have camped out on harvested fields. Here, their animals have consumed the sugarcane crop residues, and in turn, the herds have fertilized the fields while clearing them of stubble (Krätli, 2015: 49). Customarily, Maldharis have then often returned to their villages during the monsoon when jangli (wild) fodder has been more abundant. The flexibility of pastoral production systems, as well as their efficiency in using what is traditionally considered the waste of production systems, has ingeniously enabled shepherding groups of Maharashtra and Gujarat's drylands to manage the unpredictability of rainfall and frequent drought in the region better than many of their settled counterparts. They "stretch the length of the wet season" and "access discontinuous resources" using mobility (Krätli, 2015: 43).

Yet migratory life has nonetheless entailed particularly stark forms social and spatial marginality. Indeed, by the time Sangita was hosting her workshop, the sugarcane factories of the area had closed. Maldhari shepherds had moved onto new lands by making fresh negotiations with different farmers. They remained flexible, maximizing access to resources by being adaptable, but there were limits. Many of the pastoralists that I met, for example, were unable return to their home villages at that time due to fodder and water shortages. Their routes of mobility as a production strategy were uncertain. They were changing and they were precarious. This precarity compounded already existing challenges of mobile life.

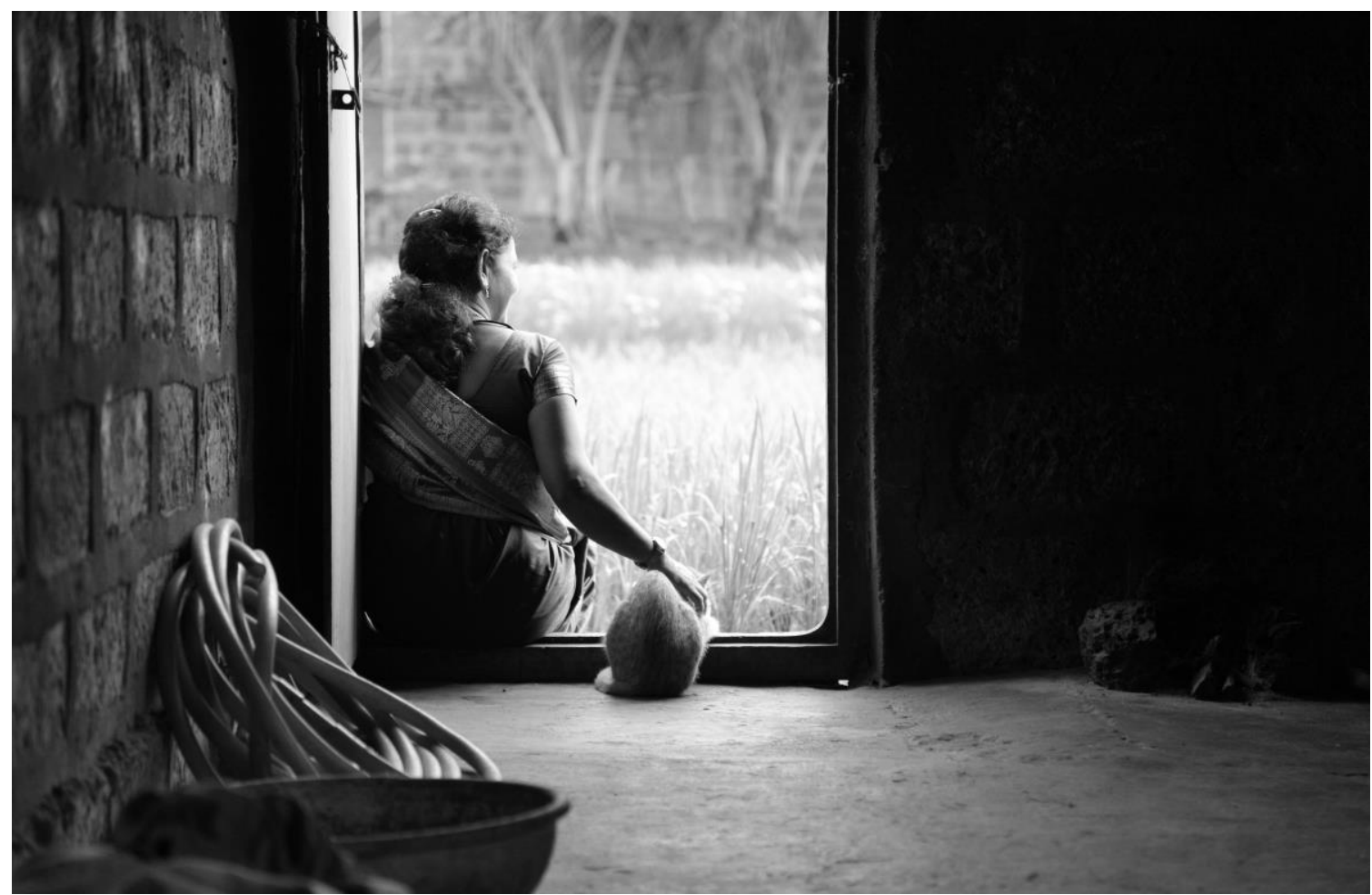

Sangita visiting her husband's village (2019). Author's photo. 
During my time with Anthra, Nitya helped me understand that mobility and legibility in the eyes of the state were difficult to reconcile. For example, a recent study by India's Ministry of Social Justice and Empowerment found that $50 \%$ of the pastoral families they surveyed did not possess caste certificates, voter identity cards, below the poverty line (BPL) ration cards, or proof of address. As such, they also could not access Aadhar cards, which are increasingly necessary for access to social welfare services, banking, and telecommunications. The question of what kinds of identification pastoralists had access was to was one that Nitya explored during my time as an intern. Nitya and the Anthra team ultimately concluded that Maharashtra's pastoral people were, "Hidden and unaccounted for."

This documented difficulty in accessing a broad swathe of social services shaped Nitya's contention that doctors and veterinary professionals were similarly inaccessible to the region's pastoralists. It was not about human and animal, it was about settled and unsettled. Being mobile, she argued, made it socially, politically, and economically necessary to address human and animal health together with inexpensive medicines that reduced production input costs and saved time otherwise spent walking from an encampment to pharmacies, clinics, and hospitals. Folk medicines, like the one Sangita was making that day, helped overcome material and immaterial barriers that these communities experienced in accessing healthcare for themselves and their animals. The oneness of my Anthra's One Health was thus not of a universalizing or generic kind. They were not interested in "the human" and "the animal" as totalizing categories. They were interested in these humans and these animals. There was no one size fits all solution, only case-by-case assessments that took into account the unique biographies of distinct illnesses, whether they be human or bovine or both. Difference and similarity only emerged in context.

\section{Human and Animal Reproductive One Health}

Indeed, with Anthra's emphasis on pastoral communities in particular, their One Health vernacular described a particular kind of encompassment with ambivalent political implications that required close attention and further study. The boundary between human and animal could be crossed, but not all shared ailments could be singularly addressed. This required knowledge, training, and discernment. In addition to questions of caste, space, and class, for Nitya, this also meant accounting for gender. Pastoral women play a crucial role in animal husbandry as they often care for pregnant ewes, goats, and cows, as well as their young lambs, goats, and calves. At the same time, according to Nitya, they experience extreme difficulty in accessing maternal and reproductive healthcare for themselves. As such, during my research, Nitya's One Health was specifically geared toward illuminating, researching, acting upon the intersections of reproductive health with livestock health.

Following a series of open-ended interviews that Nitya and her small team conducted on the "maternal health seeking behavior" of pastoral women in 2019, she argued that gender norms within pastoral communities meant women had to travel with male relatives to the doctor. Finding a chaperone compounded the already existing practical difficulties of finding the time and means to 
travel to a clinic or hospital. In addition to the difficulties of physical access, she further asserted that many women felt that the doctors disapproved of their life's mobilities. She argued that the women "were unable to follow through with the advice of the doctor in terms of filling prescriptions and not exerting themselves during pregnancy and thus felt discriminated against and patronized by many health professionals."

If doctors disapproved of their lives' mobilities, the women Nitya interviewed equally disapproved of hospital birthing norms. She wrote, "The unacceptability of hospital practices, including being forced into a supine position and the way the placenta is disposed of [...] were dissuading factors." Hospital births were, therefore, seen as undesirable; they were a last resort for the women interviewed. A complicated birth or pregnancy required a hospital, whereas a good birth was a field birth, despite the fact that it meant many children continued to be born without birth certificates and thus to be beyond the reach of social services. Encountering stigma instead of care discouraged the women that Nitya worked with from seeking out formal maternal and reproductive health professionals. Instead, she found, their "health seeking behaviors" were forged in relation to the ways in which they looked after and mothered their animals.

For example, in one workshop that Anthra organized, pastoral women were gathered in order to share strategies for managing health and illness beyond the bounds of a clinic or hospital. Women from Himachal Pradesh, Gujarat, and Maharashtra all attended. When asked about their health, many of the women emphasized their strength and immunity. As one Maldhari woman of the rabari caste put it, "We are resilient because we migrate." More than this, many women emphasized that they were resilient because living and caring for animals taught them how to do so for themselves. Women of all three groups, for example, asserted that they had seen animals giving birth their whole lives. This, they declared, gave them confidence for field deliveries. As Nitya later put it, "Their proximity to living animals, and being constant witness to the birth of lambs, chickens, and puppies, made them more familiar with the birthing process. They did not believe it to be a potentially lifethreatening situation." Watching animals give birth was a source of knowledge and empowerment for human parturition.

One Health, in this context, named a specific kind of togetherness, one of shared disenfranchisement and neglect on the one hand, and possibility on the other. Anthra's program specified hierarchies of gender, caste, and geography that fractured the category of the citizen body politic - those who are counted and accounted for in the delivery of social services - such that certain humans and animals were drawn closer together through their mutual exclusion. Nitya was not interested in this drawing together as a generic or abstract process, but rather, as one that took place in situated contexts where humans and animals shared what Alfred Schutz defined as a lifeworld, which is to say, "An intersubjective world in which people both create social reality and are constrained by preexisting social and cultural structures." In the case at hand, these were social and cultural structures that were mutually immanent with the lives of animals. This more-than-human lifeworld of health and disease 
was simultaneously problematic and redemptive insofar as it was characterized by abandonment and ingenuity in the margins (Das and Poole, 2004).

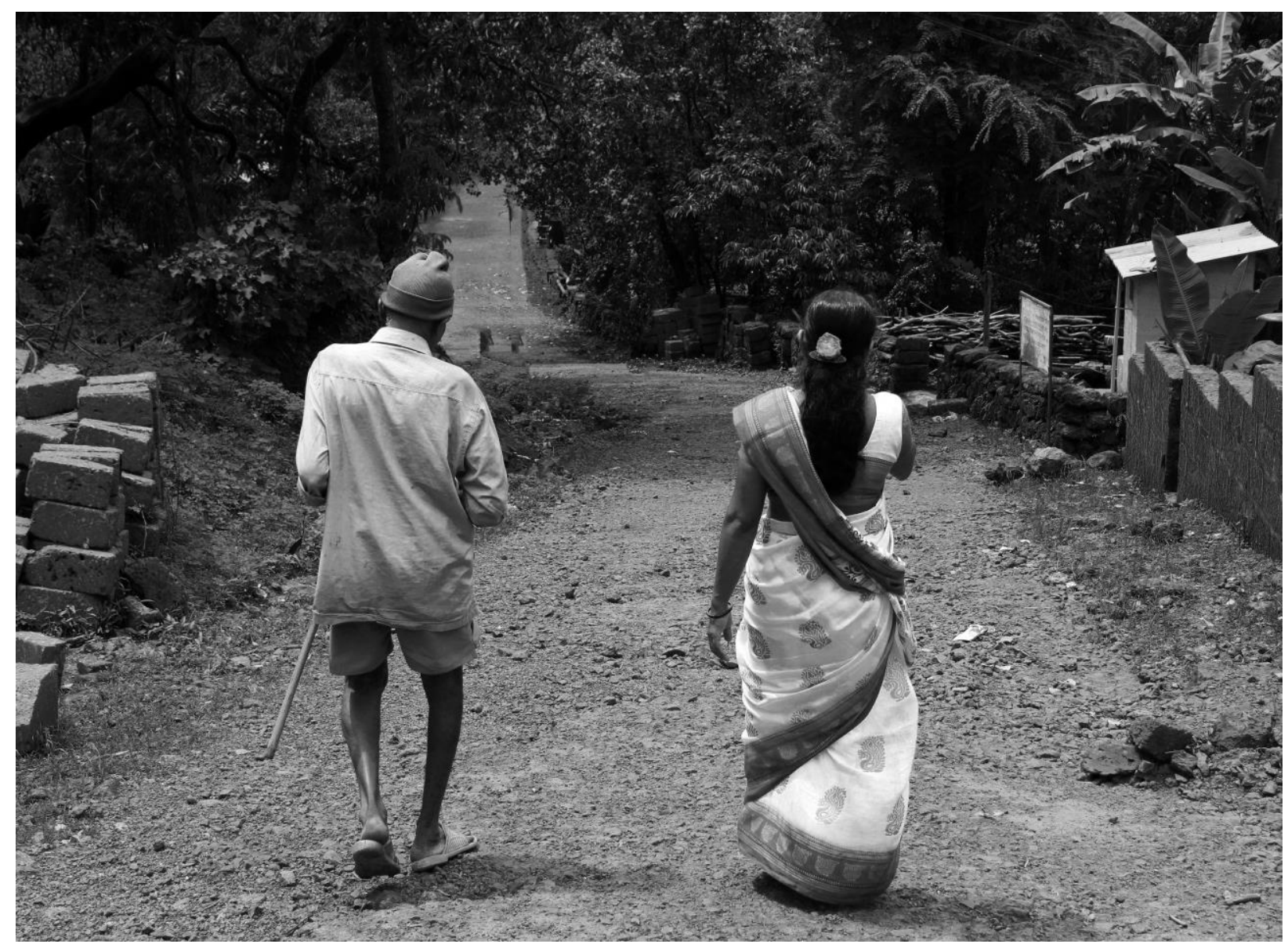

Sangita in the field (2016). Author's photo.

In this way, Nitya vernacularized One Health. By "vernacular" I do not mean to suggest that her use of this term was anything but cosmopolitan and globally-minded. Indeed, her funding for the project had come from a Christian German organization, "Misereor," a name taken from the biblical phrase, misereor super tubam, or, "I have compassion on the crowd." Moreover, she presented and workshopped her ideas internationally. Yet the way she explicitly interpreted and reframed the term meant it was a rooted concept. For "One Health" to make any sense in localized realities, it required translation. It refused to scale easily in the sense of moving from local to global without resignification (Tsing, 2004). Rather than meaning Nitya's One Health was a parochial offshoot of a Western concept that gets to pass as an unmarked universal, then, to say she vernacularized One Health is to say that Nitya made dominant renderings of the term appear equally limited.

\section{One Health}

To take a step back, a large number of reports and academic studies have been published on the subject of One Health since the early 2000s (Zinsstag et al., 2011). These reports share in Anthra's principle that wellness is not an isolated human state. Yet different from Anthra, this framework sees connections between human and animal health from above. It takes on an abstracted gaze that 
produces and naturalizes an emphasis on the Global South. Specifically, the dominant approach to One Health advocates for public health systems that might better anticipate emerging and pandemic threats. The research and writing that I encountered included diagrams, graphs, and case studies all to highlight, as emphatically as possible, the importance of global public health officials working, thinking, and problem-solving at the "animal-human-ecosystem interface" in order to improve the "governance of infectious diseases" through integrated surveillance structures. It is a paradigm of securitization, which more often than not is exclusively interested in investing time and resources in the prevention of diseases that are perceived as most likely to affect the Global North (Bankoff, 2001; Hotez and Kamath, 2009; Nunes, 2016).

In order to build prevention programs, that is, most reports and studies propose targeting "hotspots for transmission," which are almost exclusively constructed as being situated in the tropics (Ruckert et al., 2020). One Health research thus aims to correlate zoonotic disease outbreaks with specific features of a society and its environments. The idea is that, by correlating disease with socioecologies, experts will be better able to pinpoint the causes of diseases. In turn, they will be able to predict and prevent them. This work of correlation, however, requires defining quantifiable characteristics of certain environments - for example, population size or extent of mammalian biodiversity which might then be measured and correlated with disease incidence. A high rate of correlation is taken as an indicator of causal relation and predictive value.

Yet the process of coming up with and measuring "indicators" is far from a straightforward of frictionless process. In "Quantification and the Paradox of Measurement: Translating Children's Rights in Tanzania," Sally Engle Merry and Summer Wood highlight the magnitude of such a challenge. A key point of their analysis is that, to measure something, it must be countable. If cannot be counted or has not been counted, then there is a significant problem of translation (2015: 206). Moreover, the process of generating data is extremely difficult, and thus, researchers and policymakers tend to rely on datasets that already exist. For example, one study I looked at in the realm of One Health took the number of broadleaf trees in an area - an index of tropicality - as a predictive indicator. In a footnote on why these trees were taken as a predictor in this way, the authors noted that, "These reflected the most frequently hypothesized drivers of zoonotic disease emergence" (Allen et al., 2017: 7). In other words, the frequency of taking "tropical" trees as predictive lead them to also assume their causal importance and predictive value.

Such studies are biased in the simple sense of relying upon already measured factors, and in turn, upon already existing hypotheses about what may be significant (Merry, 2016: 28). It was, at least to some extent, a circular logic insofar as measuring "something" requires knowing what that "something" is. This circularity lead to an underexamined tendency for various stakeholders to emphasize the tropics in their conception of landscapes of disease. 


\section{Tropicality}

Tropicality has quickly become an organizing category for work on One Health. For example, the World Bank deployed the concept of "Neglected Tropical Diseases" and "Neglected Zoonotic Diseases," the latter being a subset of the former, in its report. Emerging in the wake of Millennium Development Goals - announced in 2000 - the terms operationally refer to diseases that "prevail in 'tropical' regions and are under-researched, under-funded, and under-treated compared with their disease burden" (Shahvisi, 2018). Philosopher and medical ethicist Arianne Shahvisi has noted that the term was initially meant to highlight neglect, and in turn, mobilize policymakers to address this class of diseases. However, as she writes,

Neglect is understood to be a passive failure, tantamount to forgetfulness, carelessness, and omission of duty. For there to be neglect, there must be referents for the neglecter and the neglected. While the health needs of the people of 'tropical' regions are undoubtedly neglected, the identity of the neglecter, and the nature of the neglect, is rarely spelled out.

The ineffectiveness of the notion of neglect has created conditions in which an emphasis on tropicality is justified. When the nature of the neglect that shapes conditions of disease are unnamed which is to say when the role of poverty, and more importantly, neocolonial relations of structural adjustment and extraction, are unspecified - it becomes easier to imagine that "tropical" regions are diseased because they are environmentally determined to be so (2018: 229-230).

For example, when elaborating on the subject, the World Bank's report succinctly concluded, "Neglected Zoonotic Diseases are endemic to many poor countries" (World Bank, 2018: 1). In this context, "endemic" was being used as an epidemiological term to suggest that certain zoonotic diseases persist at a baseline rate in these regions. Yet the term's crossover with a biological sense of endemism - denoting the extent to which a species or species ecology is unique to a particular place, belonging to it to the extent that it does not exist elsewhere - created a sense that disease belongs to the poor, and poverty belongs to the Global South as a whole (Karesh and Cook, 2005: 38-39). It territorialized disease in a way that recalled colonial discourse on the subject.

The language of tropicality, as one that encodes assumptions about the relationship between geography, poverty, and diseases that were a prevalent part of colonial public health discourses of tropical medicine and disease. In the article "Illusory Riches: Representations of the Tropical World, 1840-1950," historian of South Asia David Arnold tracked the production of the tropics as a conceptual as material space in academic writings of the mid-nineteenth and twentieth centuries. His point of focus was French geographer Pierre Gourou's "magisterial survey" from 1947, Les Pays Tropicaux (The Tropical World). Arnold argued that it illuminated how "the tropics" were produced as a homogeneous terrain of pestilence, despite acute awareness on the part of experts of the time regarding climatic diversity within countries like India. 
According to Arnold, the generalization of "the tropics" fed into a sense of environmental determinism and civilization difference. The heat and humidity of "the tropics" was posited as basically spoiling the physical and moral character of these regions (Arnold, 2000: 6). Discourses of tropical medicine posited that "Asia was an area of heat and humidity which possessed distinctive vegetation, flora and fauna, a distinctive epidemiology, and produced distinctive (distinctively undesirable) human and social characteristics" (Amrith, 2013: 98). Tropical climates created tropical diseases which were taken as evidence of "the moral and material 'superiority' of northern climates, races, and civilizations," thus justifying imperial projects of development and control (Arnold, 2000: 6, 15). Likewise, One Health interventions often use the concept of "tropicality" in discourses that similarly figured the homogeneity of certain places, people, and their connection to disease on one hand and the rightness of intervention on the other. In this way, "the tropics" are still being viewed and produced from "an external, Euro-American perspective" that justifies continued intervention in these regions in the name of their development (Arnold, 2000: 9).

\section{Mapping Disease}

The maps of One Health are often crisscrossed with arrows showing disease trajectories. They are colored in gradients of red, orange, and yellow in order to visually highlight hotspots. They are supported by legends and footnoted commentaries, explaining exactly what they mean, even though they often seem to need no interpretation. One map from 2016, circulated by the American Center for Disease Control (CDC) showed the places where their "Global Disease Detection Centers," or One Health surveillance centers, were located: India, Bangladesh, China, Myanmar, Kazkhstan, Egypt, Kenya, South Africa, and Guatemala were lit up. A different map, created by the Institute Livestock Research Institute - which only includes Africa, India, the Middle East and Asia within its purview illustrated the number of livestock keepers per square kilometer in shades of yellow to brown. Red dots that indicated areas where "one or more people or animals out of 100 are infected by one or more zoonotic diseases per year" were superimposed on this hued geography. East and West Africa, Southeast Asia, and Bangladesh were flushed with red dots (though these areas were not necessarily the most densely populated by human-animal communities).

The power of maps such as these is that they claim to reflect the world as it is. They would seem to come before and after language as a plain exhibition of objective knowledge. They naturalize an emphasis on "tropical" areas as they two-dimensionally represent what would seem to be an objecttive fact, an impartial geography. Yet as a technology of visualization and abstraction, these maps, in fact, produced an imagined geography, a conceptual space, of developed and developing, diseased and healthy, us and them. I say "imagined" not because these schemas are imaginary. There are violently material effects of such discourses. Rather, with the term "imagined," I mean to highlight the erasures and simplifications that are enabled by the translational process of mapping, as a technique of seeing from above and afar, which justify top-down, interventionist, developmental regimes of power (Allen et al., 2017: 4). 

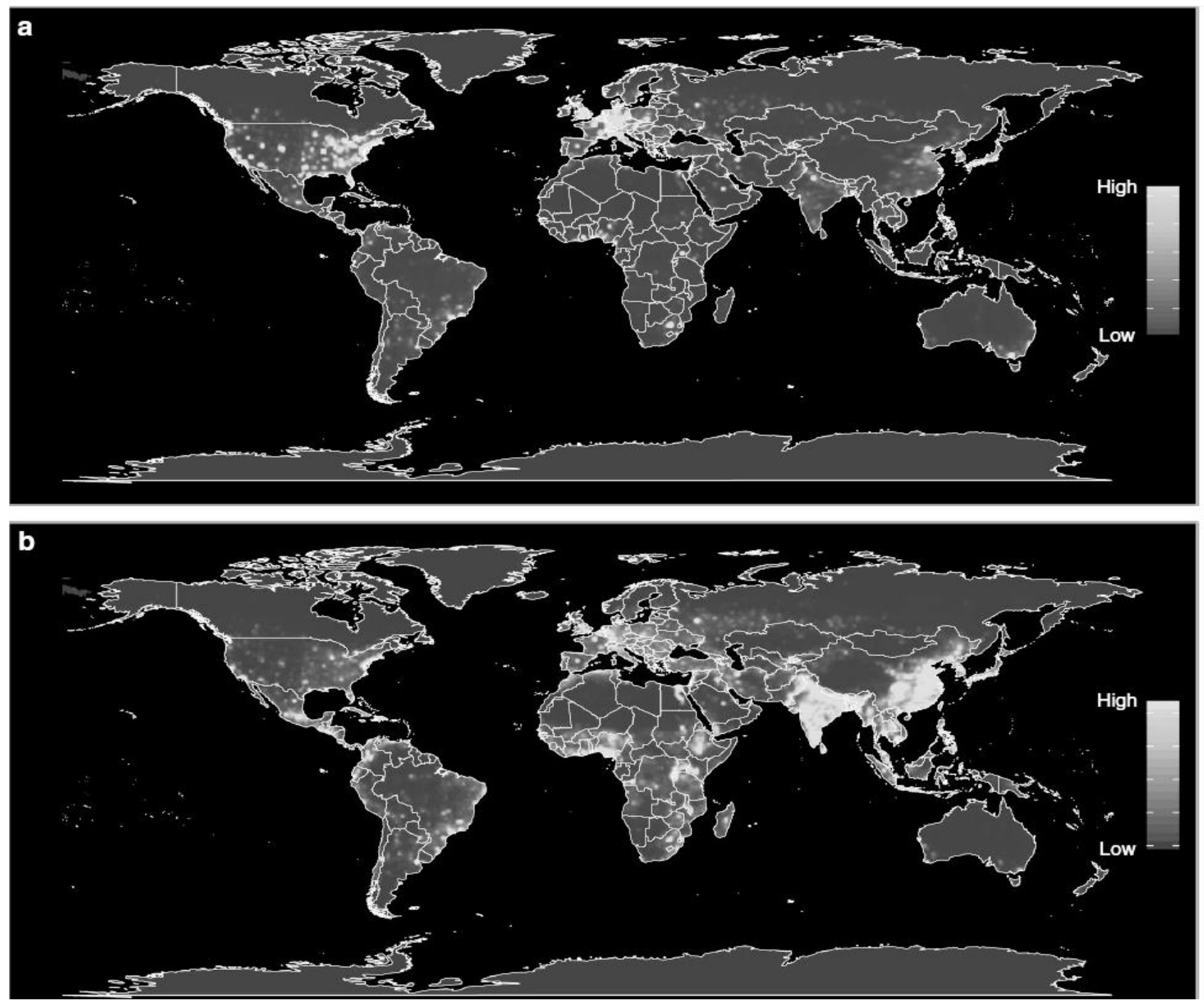

Heat maps predicting the distribution of sites of zoonotic disease outbreak.

For example, the article "Global Hotspots and Correlates of Emerging Zoonotic Disease" by Toph Allen and his colleagues sought to correlate indicators and outbreaks in a predictive model. The authors included a map illustrating their conclusions. The map they provided is a diptych: the top map represents a predicted future distribution of emerging zoonotic disease based on where events have actually been reported and correlated with indicators. The bottom map, meanwhile, predicted the future distribution of emerging zoonotic diseases "after factoring out reporting bias," which is to say, after statistically adjusting for the underreporting of disease by "poor countries." The first map shows the eastern United States, Europe, and East Asia as future sites of outbreak. The second overwhelming predicts Asia as a prospective hotspot. In correcting for reporting, the maps presume to provide an ever-more-fine-grained portrait of society. Yet the abstracted gaze of the global map - its scale at the level of a god's eye view, removed and withdrawn to see from the heavens above enables certain simplifications and erasures that work to further naturalize imperial ideologies about the innate relations between poverty, disease, and the tropics and justify the need surveillance as a public health practice. 
To start with, despite the map appearing as a diptych in the original publication, it is the second map alone - without context or explanation - that has since been circulated as visual evidence of a global landscape of disease. Indeed, in the wake of the COVID-19 pandemic of 2020, the singled-out second map, showing Asia - plain and simple - as a terrain of disease, appeared on the homepage of the EcoHealth Alliance, a "global environmental health nonprofit organization" with funding from the United States Department of Defense, and subsequently in the Netflix original documentary series, Coronavirus Explained.

On the EcoHealth Alliance's homepage, moreover, bold block lettering had been transposed onto the second map so that it now asked: "Who stands between you and the next pandemic?" The phrasing of this question assumes that future pandemics will take place. Equally, the question syntactically takes it for granted that this threat will come from a person or place that is Other to the addressee of the question. Combined with the exclusive circulation of the "corrected" map, where the fact that it has been altered is obfuscated, the image works to produce a sense that the individualized self of the West stands vulnerable, insecure, and in danger of being overtaken by invisible, foreign elements that travel from afar (Said, 1976). It anxiously asserts that we live in a world where boundaries of self and other, East and West, human and animal have been broken through viral mobilities.

That is, the map makes certain countries, communities, and people more visible and others less visible. It does so according to a medicalizing gaze that normalizes certain kinds of disease by eliminating them from the second image, implying that only diseases associated with bodies that are racialized and classed in particular ways count as posing a threat to society. The justification for this manipulation of the field of the visible is that, by adjusting for underreporting, the map is only making what must "actually" be occurring but in these zones discernible to those outside them. In other words, as a technology of visualization, the map allows for certain amplifications and erasures in its making, such that certain statistical bodies are materialized on the map as bodies to be feared, bodies in need of control, governance, and regulation.

Yet by making this correction in order to make predictions, the map is also invoking a binarized logic of whose actions constitute action in the face of disease. The many strategies of small-scale producers for managing human-animal health, as documented by Nitya, do not count. They are erased. The logic for doing so is that, in "poor countries" diseases are said to go "neglected" because they are underreported. By the same logic, the maps presume that since Euro-American countries report their disease, they can be written off as sites of potential outbreak. Reporting is, in short, taken as a token indicator of whether countries are more broadly undertaking proper measures to prevent disease, where disease prevention and management has therefore been reduced to strategies to surveil and control. 
Indeed, steeped in an ethics of suspicion and securitization, the diagrams, reports, and studies undertaken in the name of One Health justify the implementation of targeted programs of "biosurveillance." This is necessarily to be done by international development organizations in "developing" countries. With the Enlightenment idea in hand that vision is a salubrious tool for self- control and discipline, surveillance is taken to be a legitimate public health practice and policy (Foucault, 1975; Scott, 1998; Ticineto-Clough et al., 2011). In these contexts, projects to surveil collectives of humans, animals, environments, and microbes - that are threatening because they are unknown do not take the form of material infrastructures for surveillance, such as an airport scanner, CCTV, or facial recognition software. Rather, they rely on the perpetually incomplete project of generating, managing, and circulating data.

Data - in the form of statistics, maps, and reports - constitute the surveillance of One Health. It has been and is being created through scientific studies funded by international development organizations. These studies have, for example, begun to tag, track, and analyze the movement of wildlife that can act disease vectors, such as bats (EcoHealth Alliance, 2020). Information is interpreted, circulated, and managed through increasingly complex databases and interactive maps regarding histories and geographies of outbreak. Again, much of this is funded by international nonprofits in lock step with defense budgets. One Health reports, too, are an important aspect of "data-veillance" insofar as reporting on underreporting depends upon a scrutinizing gaze that justifies the need to police marginal livestock rearing communities while industrial operations - known sites of risk for emerging zoonotic disease - go relatively unchecked.

Ultimately, this growing body of data extends the institutionalized tradition to surveil the bodies of people who are Othered - and to enroll them in projects to surveil themselves and their neighbors insofar as the information gathered helps materialize certain bodies in certain ways and conceal others (Dubrofsky and Magnet, 2015: 27). It naturalizes particular ways imagining, encountering, and fearing these bodies so as to justify their control and regulation. We might say then that field of the visible, what it is possible to see and ignore, is thus shaped by racist, heteronormative, and ableist epistemological hegemonies (Butler, 1993; Puar, 2011).

Frightening bodies of the Other are made legible and illegible - they are seen, imagined, and felt through the eyes, as well as the mind's eye, as culturally-molded faculties of interpretation and projection (Ahmed, 2004). The map thus does not just reflect a factual distribution of disease, but rather, creates an imagined geography of fear, Otherness, and risk that justifies surveillance. In this way, the data-veillance of One Health operates according to a visualizing practice that has been central to regimes of power - from capitalism to ethnography - which, as philosopher Laura Marks put it, is "a sort of instrumental vision that uses the thing seen as an object for knowledge and control." Yet as Marks and others have pointed out, vision is not one thing. Indeed, major differences between dominant iterations of One Health and its face at Anthra had to do with differences in seeing as aspects of recognizing and managing disease. 


\section{Seeing with the Body}

In the book, Skin of the Film: Intercultural Cinema, Embodiment, and the Senses, Laura Marks sought to recover a fuller sense of what it might mean to look and see. She investigated the way in which many of the films that make up a core canon of intercultural cinema are sensorially counterhegemonic insofar as they "aim to represent configurations of sense perception different from those of modern Euro-American societies, where optical visuality has been accorded a unique supremacy" (2000: xiii). For Marks, these films embodied a kind of "haptic visuality" that is contrary to the Enlightenment tradition of ocularcentrism. This is a visuality capable of summoning the tactile, one that might represent non-visual registers of experience by being co-constituent with perceptual registers of the body beyond sight, including touch, smell, and taste (2000: 129). Here, seeing does not just enroll the eyes, but rather, the whole corporeal sensorium. Visuality, in Marks's writing, thus emerges as something more than a mere technology of control.

Indeed, what is most radical about a haptic kind of vision, Marks argued, is that it helps reimagine how sight might work as a tender opening unto the world. It evokes a "model of subjectivity [that] posits a mutual permeability and mutual creation of self and other" (2000: 144). That is, when the eye's relations with enfleshed perceptual landscapes of touch, smell, taste, and memory are foregrounded, to see becomes thinkable as an act that makes the body vulnerable in the world. Seeing with the body requires being open, porous, and coextensive with that which would seem to be external to it. Vision begins and ends beyond the eye itself. For Marks, the embodied mutualism of haptic visuality thus brings into focus a process by which self and world are reciprocally made, unmade, and remade in moments of "yielding-knowing," where the concept of yielding-knowing evokes epistemologies of submission rather than domination. "The perceiver relinquishes power over the perceived" (2000: 149).

When I think of Sangita's knowledge of plants, bodies, and their interactions with each other, I think of yielding-knowing. I think of her hands, worn with skill, rubbing a balm into an aching shoulder; knowingly thumbing a tulsi plant, telling me about its properties and potential; gently holding a baby chick. Each moment involved sight, but also, touch. Her knowledge was in her hands as much as her head. To know through touch is to also allow oneself to be touched, even if it is your hand that is extended out. In the context of disease, moreover, it is to allow oneself to be at risk of contagion, illness, and disease. Sangita's healing practice required yielding to this fact contagion. She was unafraid. Her and Nitya's practices of activism and care drew a riotous number of animals, plants, and people in close to them. They were subject to the world and subject of it. They were willing to simply be present in sickness and in health, to hear real people in real time talk about their problems even when these problems led them in unexpected directions. It was to allow oneself to be transformed, to become undone. 


\section{Conclusions}

One time, Sangita, Nitya, and myself wound our way up the Western Ghats in our hired car with the windows down. The air was wet and warm. The mist on the hills was gustatory; a dew to make the mouth water. It hung heavy and thick whipped around the top of mountains and floating lightly off the edges. The muddy streams were overflowing and women were out in the fields transplanting rice. Gods engraved into big red stones watched over them from the spots where they once appeared. Monsoon had just arrived and the world seemed to being saying, aaah.

We were on our way to meet Hanumantha, a farmer organizing - or trying to organize - an organic dairy in his village. He had requested Anthra's pamphlets on Ayurvedic and folk remedies for ailments experienced by livestock and their keepers. Hanumantha grew an immense number of organic vegetables for himself and his family. Sangita and I developed a list a page long: ridge gourd, bottle gourd, red gourd, bitter gourd, broad beans, peas, cabbage, fenugreek, turmeric, black beans, cucumber, onion, tomatoes, eggplant, rice, and things with Marathi names that had no counterpart in English. He grew elephant grass and sugar cane for his animals, and made trades with other farmers - usually ones without animals - for other kinds of fodder, such as, sorghum and corn. He also owned land and relatively large herd of eight Jersey-Holstein crossbred cows, two bulls, and seven calves. Hanumantha used the dung of his herd to fertilize his field and the labor of his two oxen to prepare it.

His connection with his animals was close, though not romantically so. It was an intimacy that arose out of the reality of life and its everydayness. The material structure of his home was telling in this regard. His house consisted of three adjoining rooms: A kitchen, living room, and cattle shed. He had taken out a seventeen-lakh rupee loan - approximately $\$ 25,000$ USD - to add the cattle shed onto his home. The shed was both a marker of modernity and a new necessity made requisite by the fact that Hanumantha had decided to invest in a more intensive method of production. Six years earlier Hanumantha had switched from rearing buffalo (murrah) to purebred Jersey cows because, he explained, while buffaloes produce more milk - worth more per liter because of its fattiness - they also have longer gestation times. This affects not only how quickly one can reproduce a herd but also how frequently buffaloes give milk. Yet his decision to switch to Jerseys was costly. The purebred animals did not fare well in their new hilly, rainy home. All suffered from mastitis so severe - caused, in part, by moisture - that he had to replace his herd again. Replacing his herd for a second time, Hanumantha opted for Jersey-desi mixes. While many experts claim that these hybrid animals contain the best of both desi and exotic worlds as it were, Hanumantha was taking no chances and built them a shelter to better protect them from the elements.

Yet the debt that Hanumantha incurred as a result of his herd's need for a hi-tech shelter put him on the brink of financial and emotional collapse. He explained to the team, "I have tried to do things in different ways, but I have not been able to come up with a profitable solution. I am unable to make ends meet. I don't have any household items for entertainment, or a lifestyle of leisure. I don't even 
have a TV. I can't change any of this. People drink Rs 400 worth of alcohol. I have to think twice before having an extra cup of tea. If, after doing all this, there is no satisfaction in my job [...] " he trailed off. Nitya picked up the thread, "Yes, if you don't even have any satisfaction, then it is difficult." Hanumantha, encouraged, responded, "Yes, from 4 or 5 in the morning until the evening we are all working hard, just working [...] We live on the field. We live here due to our cattle." He pointed to his daughter who had flitted around the edges of the room, giving and taking cups of tea, "This is my daughter," he said, "She is unwell. She got wet in the rain and has caught a cold and fever." Sangita, Nitya, and I all smiled with as much warmth as we could summon.

Nitya lit up, "Let us teach her! She can learn how to use local, natural medicines. It will reduce your expenses." "Sure," Hanumantha replied, "Why not?" He stopped abruptly, just then his daughter shook her head. "She says no!" He laughed. Nitya bristled, "These days, everyone wants to go to the city and learn computers. It such a fad." Perhaps lightened by his daughter's insouciance, Hanumantha changed his tack. "Yes, the world is changing so fast," he agreed. "But I am satisfied that in my house, apart from minor seasonal illnesses, there is no blood pressure, diabetes, and other such illnesses. There is so much change," he continued. "Strange illnesses that we never knew of. Nowadays there are no children without a caesarian section. Unlike in our case, my wife was carrying a basket of cow-dung, working in the fields when her water broke and she delivered right there: No hospital expenses. She had a robust constitution. It gives me a sense of satisfaction that, here, our health is still good."

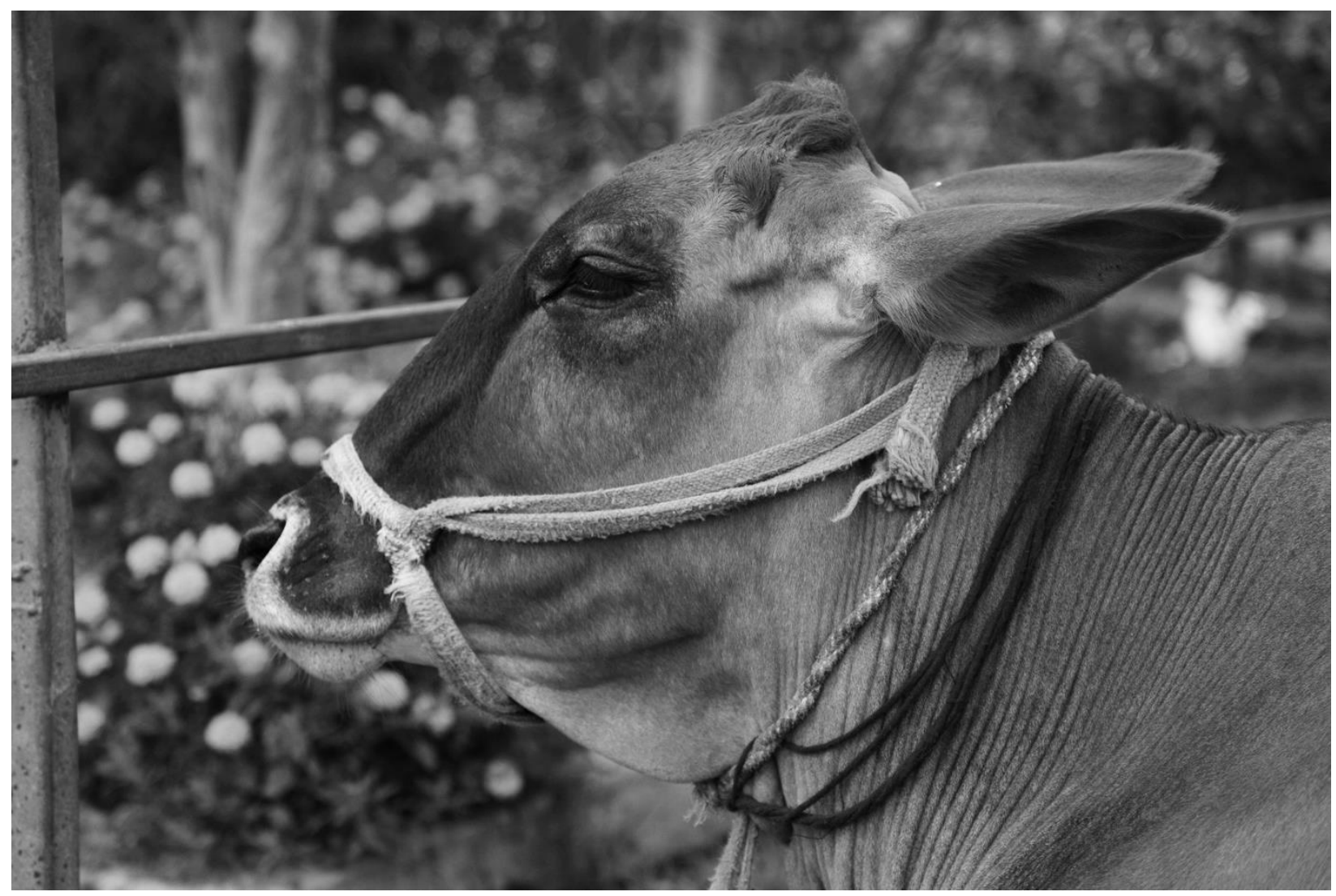

A Jersey-desi mixed breed cow (2019). Author's photo. 
Reversing the assumptions of One Health that poverty and human-animal intimacy mean disease must run rampant, Hanumantha asserted the opposite: It was rich people and urban places that were diseased. In fact, animal proximity to humans was key to their wellbeing. After a brief silence in the conversation, Hanumantha continued, "Last night there was a snake, it was a cobra. We got some villagers and killed him. It was the cow who warned us all." He paused as we all gazed into the shed, tails quietly swishing, chomping away on dry fodder. He continued, "It's a balance of nature: we look after the animals, who in turn help us." He then repeated, "It's a balance of nature, an inter-relationship (sambandh)." Here sambandh articulates a way of knowing that was mutual, a kind of sharing that was not blighted.

Indeed, the longer I followed Nitya and Sangita, the more I began to understand that, rather than zoonotic diseases, the sicknesses they bore witness to and sought to redress with their One Health were of a more social kind. For many producers, the risks and hardships they shared with their animals were not so much about disease per se. Recall, in her interview with shepherding women, pastoral women told Nitya that it was their proximity with their animals that enabled them to take care of themselves, a vital necessity since they were more or less abandoned by the state and its social services for health and veterinary care. More than this, they said, their lives and livelihoods made them strong, made them immune. When Nitya pushed, however, wanting more detail about any health issues whatsoever that they may experience, a few told her, and then more agreed that, "The main health issues they experience are joint pain, back pain, weakness, tired eyes from embroidery, tiredness, malnutrition."

Their fatigued bodies point us to a different class of afflictions, still shared by humans, animals, plants, and environments, but beyond the current scope of One Health. Instead of biological diseases and infections, when we look and see from the perspective of the body - a real body, rooted in time and place, where the eye's connection with touch, memory, and feeling are allowed to remain intact other kinds of vulnerabilities become perceptible. All around us, human, animal, plant, and ecological bodies, particularly, those that bear the brunt of producing for a global economy of food accumulation and waste, are manifesting signs of this exhaustion and pending collapse. Rather than striving for more mastery, more control, more surveillance, however, we need to find ways to remain bound and open to this tiring planet.

An exhaustion extends across multiple kinds of bodies in the peripheries of productionism. Humans - especially those who are materially marginalized by "urban metabolisms," cycles of consumption and expulsion - do share states of wellness and sickness, living and dying, risk and possibility with their animals, their crops, their lands. For better or worse, they rely on each other in these weary times, thickly bound by the interrelations of living and its vicissitudes. This exhaustion is ignored by dominant One Health frameworks, as well as dairy development more broadly, at this time. Its manifestations are not seen by them; data bears no witness. The complex interrelationships 
that makeup this field of "waxing and waning vitalities" remain hidden and unaccounted for (Singh, 2015). To bear witness, as Nitya and Sangita taught me, was to see anew, to see differently, to see with the body and let its course be changed (Naisargi, 2012).

\section{Works Cited}

Ahmed, Sara (2004), "Affective Economies", Social Text, 22.2: 117-139.

Allen, Toph, Kris A. Murray, Carlos Zambrana-Torrelio, et al. (2017), "Global hotspots and correlates of emerging zoonotic diseases", Nature Communications 8, 1124. https://doi.org/10.1038/s41467-017-00923-8

Amrith, Sunil (2013), "Health and Sovereignty in the New Asia: The Decline and Rise of the Tropics", Medical Encounters in British India, Deepa Kumar and Raj B. Sekhar (eds.), London, Oxford University Press: 98-119.

Anthra (2016), http://www.anthra.org/focus-area/one-health/ (Accessed July 1, 2020).

Arnold, David (2000), "'Illusory Riches': Representations of the Tropical World, 1840-1950", Singapore Journal of Tropical Geography, 21.1: 6-18.

Bankoff, Gregory (2001), "Rendering the World Unsafe: 'Vulnerability' as Western Discourse", Disasters, 25: 19-35.

Butler, Judith (1993), "Endangered/Endangering: Schematic Racism and White Paranoia", Reading Rodney King/Reading Urban Uprising, Robert, Gooding-Williams (ed.), New York, Routledge: 15-22.

Das, Veena and Deborah Poole (eds.) (2004), Anthropology in the Margins of the State. Santa Fe, School of American Research Press.

Dubrofsky, Rachel E. and Amielle Magnet Shoshana (2015), "Introduction: Feminist Surveillance Studies: Critical Interventions", Feminist Surveillance Studies, Durham, Duke University Press: 118. https://doi.org/10.1215/9780822375463-001.

EcoHealth Alliance, https://www.ecohealthalliance.org. Accessed July 9, 2020.

Foucault, Michel (1975), Discipline and Punish: The Birth of the Prison, Harmondsworth, Middlesex, Penguin Books.

Hotez, Peter J. and Aruna Kamath (2009), "Neglected Tropical Diseases in Sub-Saharan Africa: Review of Their Prevalence, Distribution, and Disease Burden", PLOS Neglected Tropical Diseases, 3.8: e412. https://doi.org/10.1371/journal.pntd.0000412.

Karesh, William. B. and Robert A. Cook (2005), "The Human-Animal Link", Foreign Affairs, 84.4: 3850.

Krätli, Saverio (2015), Valuing Variability: New Perspectives on Climate Resilient Drylands Development, International Institute for Environment and Development (IIED).

Livingston, Judith and Jasbir Puar (2011), "Interspecies", Social Text, 29.1: 3-14.

Marks, Laura U. (2000), Skin of the Film: Intercultural Cinema Embodiment and the Senses, Durham, Duke University Press. 
Merry, Sally Engle and Summer Wood (2015), "Quantification and the Paradox of Measurement: Translating Children's Rights in Tanzania", Current Anthropology, 56.2: 205-229.

Merry, Sally Engle (2016), The Seduction of Quantification: Measuring Human Rights, Gender Violence, and Sex Trafficking, Chicago, University of Chicago Press.

Naisargi, Dave N. (2012), "Witness: Humans, Animals, and the Politics of Becoming", Cultural Anthropology, 29.3: 433-456. https://doi.org/10.14506/ca29.3.01.

Nunes, João (2016), "Ebola and the Production of Neglect in Global Health", Third World Quarterly, 37.3: 542-556. https://doi.org/10.1080/01436597.2015.1124724.

Puar, Jasbir (2011), "The Turban is not a Hat: Queer Diaspora and Practices of Profiling", Beyond Biopolitics: Essays on the Governance of Life and Death, Patricia Ticineto-Clough and Craig Willse (eds.), Durham, Duke University Press: 65-104. https://doi.org/10.1215/9780822394235004.

Ritzer, George and Jeffrey Stepnisky (2018), Sociological Theory, Los Angeles, Sage Publishing.

Scott, James C. (1998), Seeing Like a State: How Certain Schemes to Improve the Modern Condition Have Failed, New Haven, London, Yale University Press.

Shahvisi, Arianne (2019), "Tropicality and Abjection: What Do We Really Mean By 'Neglected Tropical Diseases'?", Developing World Bioethics, 19: 224-234. https://doi.org/10.1111/dewb.12223.

Singh, Bhrigupati (2015), Poverty and the Quest for Life: Spiritual and Material Striving in Rural India, Chicago, University of Chicago Press.

Ticineto-Clough, Patricia and Craig Willse (eds.), (2011), Beyond Biopolitics: Essays on the Governance of Life and Death, Durham, Duke University Press.

Tsing, Anna (2004), Friction: An Ethnography of Global Connection, Princeton, Princeton University Press.

World Bank (2018), One Health: Operational Framework for StrengtheniWng Human, Animal, and Environmental Public Health Systems at Their Interface, The World Bank, https://documents1.worldbank.org/curated/en/703711517234402168/pdf/123023-REVISEDPUBLIC-World-Bank-One-Health-Framework-2018.pdf.

Zinsstag, Jakob, Esther Schelling, David Waltner-Toews and Matthew Tanner (2011), "From 'one medicine' to 'one health' and systemic approaches to health and well-being", Preventative Veterinary Medicine, 101.3-4: 148-156, 10.1016/j.prevetmed.2010.07.003 